\title{
RNAi AND mIRNA PATHWAYS IN PLANTS II - MOBILITY OF SMALL RNAS
}

Keywords: dsRNA, miRNA, siRNA, Dicer, Argonaute, RdRP, systemic RNAi, phloem

\section{PETR SVOBODA}

Institute of Molecular Genetics, Academy of Sciences of the Czech Republic, Videnska 1083, 14220 Prague 4, Czech Republic

Correspondence to: Petr Svoboda, Institute of Molecular Genetics ASCR, Videnska 1083, 14220 Prague 4, Czech Republic, tel. \#+420 241063147, e-mail: svobodap@img.cas.cz.

\begin{abstract}
RNA silencing denotes sequence-specific repression mediated by small RNAs. Plants have arguably the most complex RNA silencing among eukaryots because of existence of many paralogs of key protein factors, which form in an intricate network of primary and secondary small RNAs, which mediate transcriptional and post-transcriptional effects, which target endogenous protein-coding gene expression, serve as a form of innate immunity targeting viruses, and protect genome integrity by repressing retrotransposons. The complexity of RNA silencing was introduced in an accompanying review. Here, I will focus on mobility of small RNAs in plants, which allows for silencing effects occurring at a different place than where the silencing was initiated. I will discuss different types of mobility of different classes of small RNAs across plant tissues and their biological implications.
\end{abstract}

\section{Introduction}

RNA silencing in plants is highly complex thanks to existence of many Dicer, Argonaute, and RNA-dependent RNA polymerase (RdRP) paralogs, which fucntion in a network of primary and secondary small RNAs, which mediate transcriptional and post-transcriptional effects (Fig. 1). The nomenclature of small RNAs in plants is complex and arbitrary; small RNAs include miRNAs and various types of siRNAs produced from dsRNA, which are distinguished by their origin (viral siRNA), biogenesis (phased siRNAs) or their effect (heterochromatinizing siRNAs). RNA silencing in plants can be divided in three to four main systems: miRNA, RNAi/ post-transcriptional gene silencing (PTGS), antiviral defense/virus-induced gene silencing (VIGS), and transcriptional gene silencing (TGS) (Bologna and Voinnet, 2014; Bonnet et al., 2006; Borges and Martienssen, 2015; Carbonell and Carrington, 2015; Chen, 2009; Galun, 2005; Mallory et al., 2008; Van Ex et al., 2011; Vazquez, 2006; Zhang 


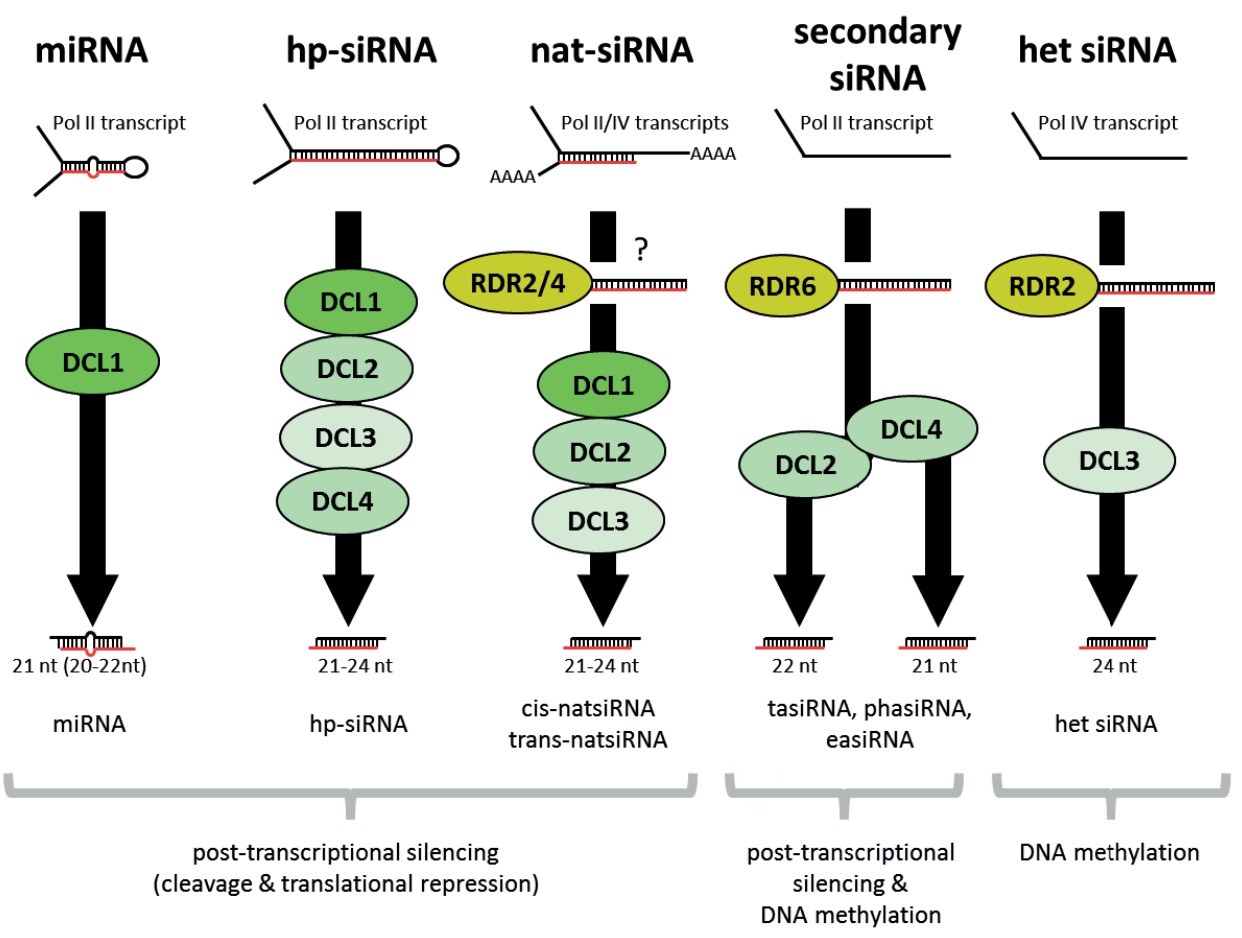

Figure 1 Complexity of small RNAs in plants. The scheme was adapted from (Borges and Martienssen, 2015)

et al., 2015). The complexity of small RNA biology was reviewed in the first plant RNA silencing review (Svoboda, 2019). Here, I will focus on mobility of small RNAs in plants.

\section{Plant anatomy and features relevant for movement of molecules}

Plants are unique in several aspects when compared to cells of other eukaryotic organisms. Plant cell features important for intercellular exchange of molecules include a polysaccharide cell wall and plasmodesmata. The latter are microscopic channels traversing cell walls of plant cells allowing for movement (symplastic movement or symplast) of molecules between adjacent cells (reviewed in Maule, 2008; Maule et al., 2011). An alternative to the symplastic movement, which involves cell cytoplasm, is apoplastic movement (apoplast) where molecules move through cell walls and intercellular space.

A flowering plant (Fig. 2) consists of three anatomical systems - root, shoot, and inflorescence. It is anchored by a root, absorbs water and minerals from the grounds and transports them through the xylem vasculature through the plant and into leaves, which are the main photosynthetic organs. Sugars produced in leaves are transported around through the phloem vasculature. 
Structurally, plant tissues are divided into meristems (containing actively dividing cells, thus being the primary place of plant growth) and permanent tissues classified according to their shapes and intercellular space.

Long distance movement of molecules occurs through the aforementioned vascular system, which transports water, mineral, signaling molecules, nutrients, and other molecules. In particular, phloem is the main avenue for transporting organic molecules (discussed in (Atkins et al., 2011; De Schepper et al., 2013; Turgeon and Wolf, 2009)). There is a large number of mobile macromolecules in plants. In an effort to provide a systematic catalogue of mobile macromolecules, a database PlaMoM was compiled, which provides convenient and interactive search tools allowing users to retrieve, to analyze and also to predict mobile RNAs/proteins (Guan et al., 2017). The current version compiles a total of 17,991 mobile macromolecules from 14 plant species/ecotypes and is available at: http://www.systembioinfo.org/plamom/.

\section{Distribution of RNA silencing pathways across plant tissues}

Plants expressed multiple AGOs, DCLs and RDRs, which support different types of RNA silencing pathways employing different types of small RNAs (Fig. 1). Plant small RNAs are typically methylated at the 3' end, which protects them from degradation (Li et al., 2005). Plant RNA silencing pathways can be divided into miRNA and siRNA pathways, which use distinct small RNA substrates. From the perspective of small RNA populations originating from different substrates, two distinct types of small RNAs can be recognized when considering their sequence prediction (Fig. 3): The first type, exemplified by miRNAs, comprises small RNAs, which occur in cells in many identical copies (i.e. with the same sequence). The second type, exemplified by siRNAs derived from dsRNA, is characterized by existence of populations of small RNAs with variable sequences, which originate from a longer sequence. Although their sequences could be determined, their individual annotation is pointless. One kilobase of dsRNA theoretically produces nearly thousand small RNAs differing at their 5' ends where each one of them could regulate a different set of genes (there is 4096 possible of a hexamer sequence). These small RNAs usually function as a defense system operating on the basis (nearly) perfect complementarity.

miRNA (Fig. 4) and related pathways function post-transcriptionally and include the canonical miRNA pathway with 21nt miRNAs (utilizing DCL1 and AGO1) and its alternatives employing other DCL and AGO proteins and longer hairpin substrates.

siRNA pathways use either exogenous substrates (antiviral defense and transgene silencing, Fig. 5) or various dsRNAs derived from genomic sequences. Various biogenesis pathways produce primary and secondary siRNAs of various types and lengths $(21,22$, or $24 \mathrm{nt}$ ), which mediate post-transcriptional or transcriptional silencing. siRNA lengths are determined by the processing Dicer paralogue. $21 \mathrm{nt}$ siRNAs can be produced by DCL4 or DCL1, 22nt siRNAs by DCL2, and 24 nt by DCL3.

There is a large volume of literature concerning NGS analysis of small RNA populations from different tissues in different plant species. A large volume of NGS data can be accessed through Plant MPSS (massively parallel signature sequencing) databases website 


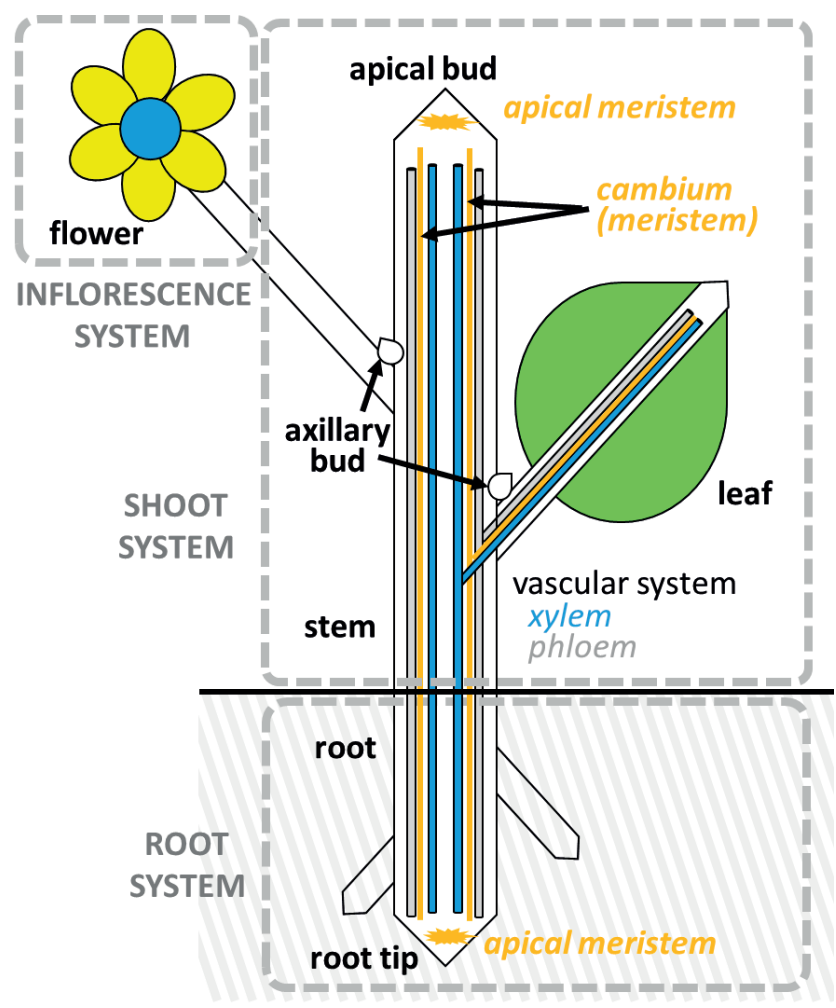

Figure 2 A schematic overview of plant body organization.

(https://mpss.danforthcenter.org/), which was introduced in 2005 (Nakano et al., 2006) and has been continuously updated and expanded. It currently contains small RNA data from 19 plant species. Most datasets in the database (six) come from analysis of small RNAs in rice. These rice datasets combine the expression atlas of rice mRNAs and small RNAs (Nobuta et al., 2007), with analysis of small RNAs during development where different pools of phasiRNAs were identified (Fei et al., 2016), a comprehensive analysis of small RNAs in different tissues under normal conditions and stress (Jeong et al., 2011) and unpublished NGS data from different rice tissues and AGO immunoprecipitates.

These and other data from rice (e.g. (Heisel et al., 2008)) reveal common and tissue-specific populations of small RNAs. The existence of tissue-specific small RNAs shows that systemic RNA silencing co-exists with RNA silencing mechanisms restricted to specific tissues. Several factors may underlie tissue specificity of particular small RNA mechanisms. These include (i) tissue-restricted expression of proteins involved in biogenesis and activity of particular small RNA class, (ii) tissue-restricted presence of substrates for biogenesis of small RNAs, and (iii) restriction of mobility/spreading of small RNAs, which could differ between different cell types. Next, I will briefly discuss selected specific examples, which provide an insight into the complexity of the issue: 


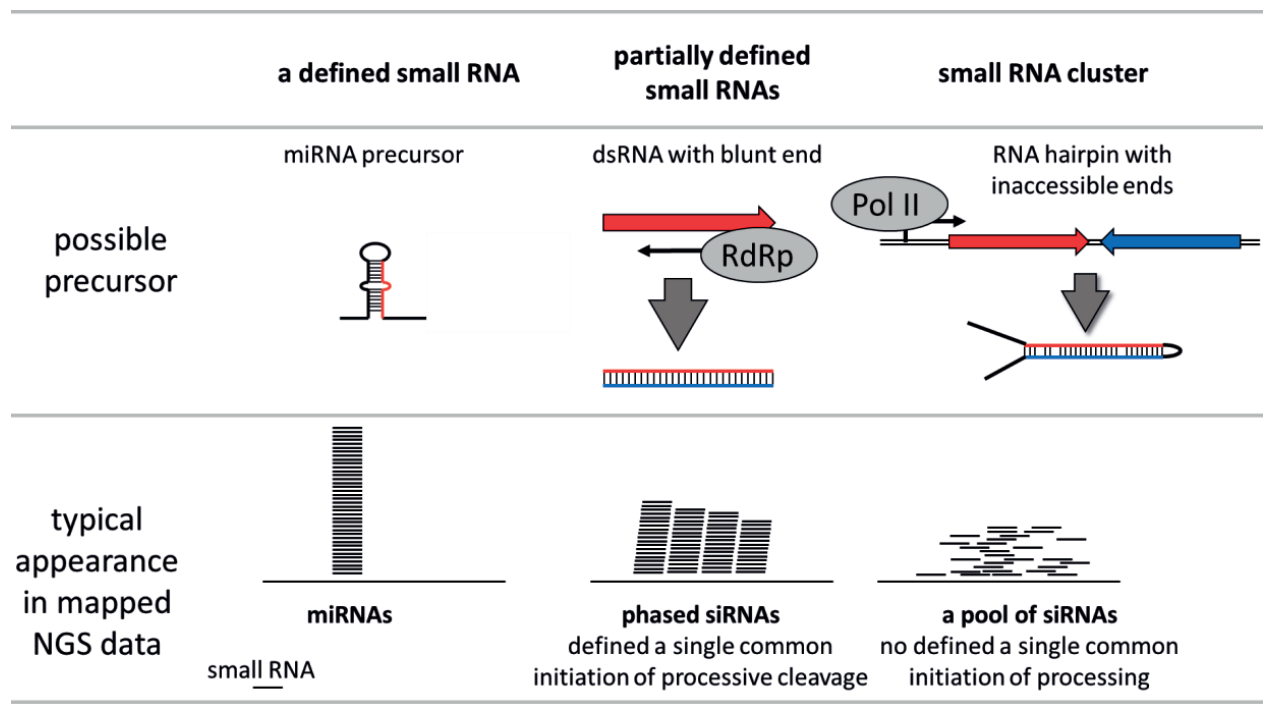

Figure 3 Distinct types of small RNAs differing in occurrence of RNAs with identical sequences

\section{Tissue-restricted expression of protein factors involved in small RNA biogenesis and activity}

While many genes encoding factors involved in small RNA biogenesis (e.g. Dicers, RDRs) and function (e.g. Argonautes) of small RNAs are ubiquitously expressed, some exhibit preferential or tissue restricted expression. For example, a systematic analysis of gene expression was done in Arabidopsis and rice (Kapoor et al., 2008), where microarray profiling identified several differentially expressed factors during development and in different tissues. Similar data could also be extracted from available NGS profiling of mRNAs at the aforementioned website (https://mpss.danforthcenter.org/). In general, these expression data have predictive value mainly for specific Argonaute paralogs, which host unique small RNA pools and have highly restricted expression patterns.

\section{Tissue-restricted presence of substrates for biogenesis of small RNAs}

This factor involves localization of exogenous small RNA substrates to different tissues (i.e. viral infections and transgene expression) or expression of endogenous small RNA substrates. This allows, for example to differentiate expression of subpopulations of small RNAs in time and space. A classic example is tissue-specific expression miRNAs, whose precursors are transcribed by polII polymerase and thus can exhibit tissue-restricted expression as mRNAs. As there is a large volume of the literature on miRNA expression in plants, which is beyond the scope of this report, I only select illustrative examples of analyses of tissue-specific expression of miRNAs in rice .(Mittal et al., 2013; Zhu et al., 2008), Nicotiana (Valoczi et al., 2006), and Arabidopsis (Grant-Downton et al., 2009; Valoczi et al., 
2006). Tissue-specific expression of small RNAs can be observed for tasiRNAs, which originate from specific loci (Marin et al., 2010; Zabala et al., 2012) or phasiRNA, where a specific miRNA initiates production of phasiRNAs (Fei et al., 2016).

\section{Restriction of mobility/spreading of small RNAs.}

Restriction of mobility assures that tissue/cell-specific expression will remain contained. There are several cell types, from which small RNAs do not seem to be spreading around. These include guard cells of stomata (Voinnet et al., 1998), endosperm (energy storage of the seed) (Hournard et al., 2007) or the seed coat (Tuteja et al., 2009).

\section{Movement of small RNAs between cells and tissues - miRNA mobility}

miRNAs can also be transported over long distances but this is not a universal rule for all miRNAs (Buhtz et al., 2008; de Felippes et al., 2011; Knauer et al., 2013; Lin et al., 2008). Analysis of the phloem sap of oilseed rape Brassica napus identified 32 annotated microRNAs (miRNAs) from 18 different families (Buhtz et al., 2008). In addition, the levels of three mature miRNAs known to respond to nutrient deprivation in non-vascular tissue, MIR395 (sulphate), MIR398 (copper) and MIR399 (phosphate), were increased in phloem sap during the growth of plants under the respective nutrient deprivation (Buhtz et al., 2008). Other known mobile miRNAs in Arabidopsis are MIR394, which is produced by the surface cell layer and contributes to shoot meristem formation (Knauer et al., 2013), and MIR165, which regulates differentiation (Miyashima et al., 2011).

MIR395 and MIR399 mobility through phloem was demonstrated in grafting experiments while MIR171 was not transported (Buhtz et al., 2010; Pant et al., 2008). Consistent with phloem movement, another analysis of miR399 movement using reciprocal grafting in Arabidopsis suggested that it moves from shoots to roots (Lin et al., 2008).

The basis of selectivity underlying miRNA mobility in plants remains unclear. It was shown $22 \mathrm{nt}$ artificial miRNAs derived from asymmetric duplexes mediate widespread silencing of their cognate gene more efficiently than $21 \mathrm{nt}$ siRNAs from symmetric duplexes (McHale et al., 2013).

\section{Movement of small RNAs between cells and tissues - systemic RNAi in plants}

RNAi can either act in a cell autonomous manner, i.e. affecting only cells directly exposed to dsRNA, or can propagate across cell boundaries. Early observations of co-suppression in petunia (Jorgensen, 1995; Napoli et al., 1990) and antiviral resistance in Nicotiana benthamiana (Ratcliff et al., 1997) suggested that RNA silencing in plants includes a mobile silencing signal. Several studies subsequently confirmed that transgene-induced silencing is mobile (Palauqui et al., 1997; Voinnet and Baulcombe, 1997; Voinnet et al., 1998, 2016). These experiments used grafting and agroinfiltration strategies to show that silencing 
spreads from the lower silenced leaves to the upper non-silenced leaves (Palauqui et al., 1997; Voinnet and Baulcombe, 1997). Based on the distance of silencing spread, short range and long range/systemic spread can be distinguished (Fig. 6).

\section{Short range silencing}

Short range silencing manifests as RNA silencing in a defined area. It was shown that a short-distance spreading of RNA silencing, once initiated from a small group of cells, can spread over 10-15 cells independently of the presence of cognate transcripts (Himber et al., 2003). Short range silencing was observed for both transgenes and endogenous genes (Dunoyer et al., 2007; Kalantidis et al., 2006; Ryabov et al., 2004; Schwach et al., 2005; Smith et al., 2007).

Regarding the nature of the short-range mobile signal, it is still a matter of debate. Initially, it was proposed that short range spreading involves DCL3-dependent 24nt siRNAs (Hamilton et al., 2002; Molnar et al., 2010). Subsequently, DCL4-dependent $21 \mathrm{nt}$ siRNA were also implicated in short-range spreading (Dunoyer et al., 2007; Dunoyer et al., 2005; Himber et al., 2003; Smith et al., 2007). It was shown that they are sufficient for the limited moving of the silencing and that the short range silencing is independent of an RdRP SDE1 and helicase SDE3 (Himber et al., 2003). Furthermore, it was suggested that the mobile signal is are siRNAs themselves ant not their longer precursors and AGO-bound single strand molecules but this evidence came in one of the recently retracted papers (discussed in Addendum at the end of the review).

Besides 21 siRNAs, several other types of plant small RNAs can spread cell-to-cell. These include miRNAs (discussed separately further below), tasiRNAs of the TAS3 locus (Chitwood et al., 2009; de Felippes et al., 2011; Marin et al., 2010; Schwab et al., 2009).

In terms of the mechanism of cell-to-cell silencing movement, early studies implied that post-transcriptional silencing spreads through plasmodesmata (Palauqui et al., 1997; Voinnet et al., 1998). However, the amount of evidence for cell-to-cell silencing movement through plasmodesmata is rather moderate. Support for the symplastic movement through plasmodesmata comes from an observation that symplastically isolated guard cells of stomata escape short-range spreading (Himber et al., 2003; Kalantidis et al., 2006; Voinnet et al., 1998). Furthermore, analysis of short-range spreading in Arabidopsis embryos, suggested that the spread is affected by and positively correlates with plasmodesma aperture (Kobayashi and Zambryski, 2007). While these results are in agreement with the assumption that short-range spreading of silencing occurs through diffusion and plasmodesmata, alternative routes, such as secretory vesicles should still not be excluded.

In addition, genetic analysis revealed several factors involved for cell-to-cell silencing movement (summarized in Table 1). Some of these factors were already mentioned above. Interestingly, among the factors whose mutations reduce cell-to-cell silencing movements were also RDR2 CLSY1, and NRPD1a, which are required for 24nt siRNA-mediated transcriptional silencing (Dunoyer et al., 2007; Smith et al., 2007). It was suggested that these factors might function in reception and/or downstream functional integration of mobile siRNAs in recipient cells (Brosnan and Voinnet, 2011). Another nuclear factor whose mutation affects cell-to-cell silencing movement is JMJ14, a H3K4 histone 


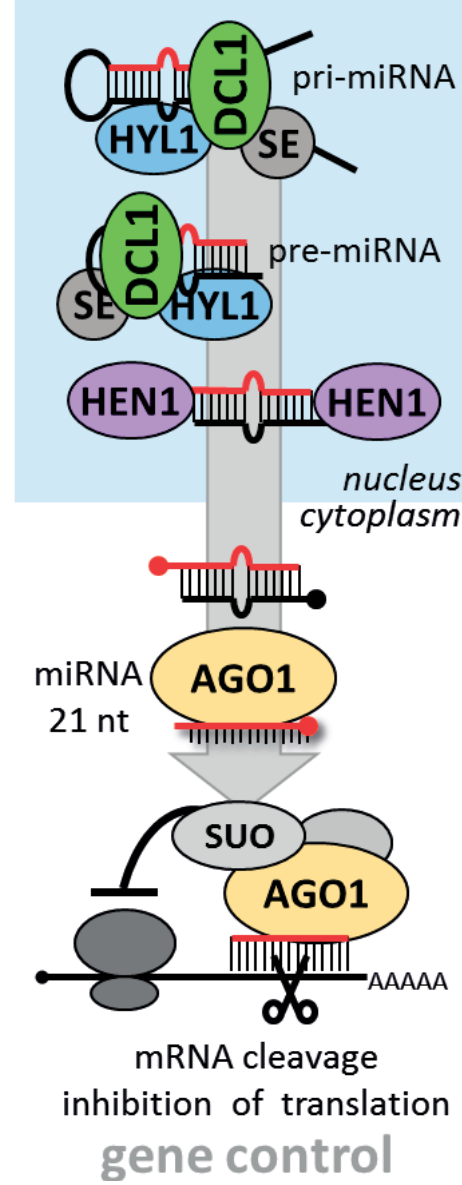

Figure 4 Plant miRNA pathway

demethylase implicated in non-CpG DNA methylation (Searle et al., 2010). However, short-range movement of tasiRNAs does not seem to require RDR2, CLSY1, NRPD1a, and JMJ14.

Taken together, while there is evidence that DCL4-dependent $21 \mathrm{nt}$ siRNAs are the mobile signal in cell-to-cell movement, cell-to-cell silencing mobility might also concern DCL3-dependent 24-nt siRNAs and other RNA molecules.

\section{Extended short-range silencing}

In addition to short-range spreading of RNA silencing, a long-range cell-to-cell movement process was also reported that occurs as a relay amplification, involving the combined activity of an RdRP SDE1 and helicase SDE3 (Himber et al., 2003). This is essentially an extended version of short-range silencing described above where the mobile signal is amplified along the way through production of secondary small RNAs (Fig. 6). This amplification process, is known as "transitivity" (Melnyk et al., 2011b). Thus, extensive and limited cell-to-cell movements of silencing are triggered by the same molecules, occur within the same tissues and likely recruit the same plasmodesmata channels (Himber et al., 2003).

\section{Long range/systemic silencing}

Plants exhibit systemic RNA silencing, which can move over long distance. This implies that a mobile silencing signal from the source tissue enters the vascular system, it is transported and then enters the recipient tissue or cells (Fig. 7). Early studies implied that post-transcriptional silencing spreads over long distance through phloem (Palauqui et al., 1997; Voinnet et al., 1998) (of note is that xylem sap, which transports water and ions, does not carry RNA (Buhtz et al., 2008)).

It was shown that transgene-specific post-transcriptional silencing is transmitted by grafting from silenced stocks to non-silenced scions (Palauqui et al., 1997). The transmission of co-suppression occurs when silenced stocks and non-silenced target scions are physically separated by up to $30 \mathrm{~cm}$ of stem lacking cognate RNAs (Palauqui et al., 1997). The systemic movement of the silencing signal takes days and typically moves from leaves (photosynthetic source) to roots and growing points (sucrose sinks) (Voinnet et al., 1998); this flow is characteristic of phloem (discussed in (De Schepper et al., 2013; Turgeon and Wolf, 2009)). Furthermore, phloem transport block by cadmium inhibits systemic silencing 


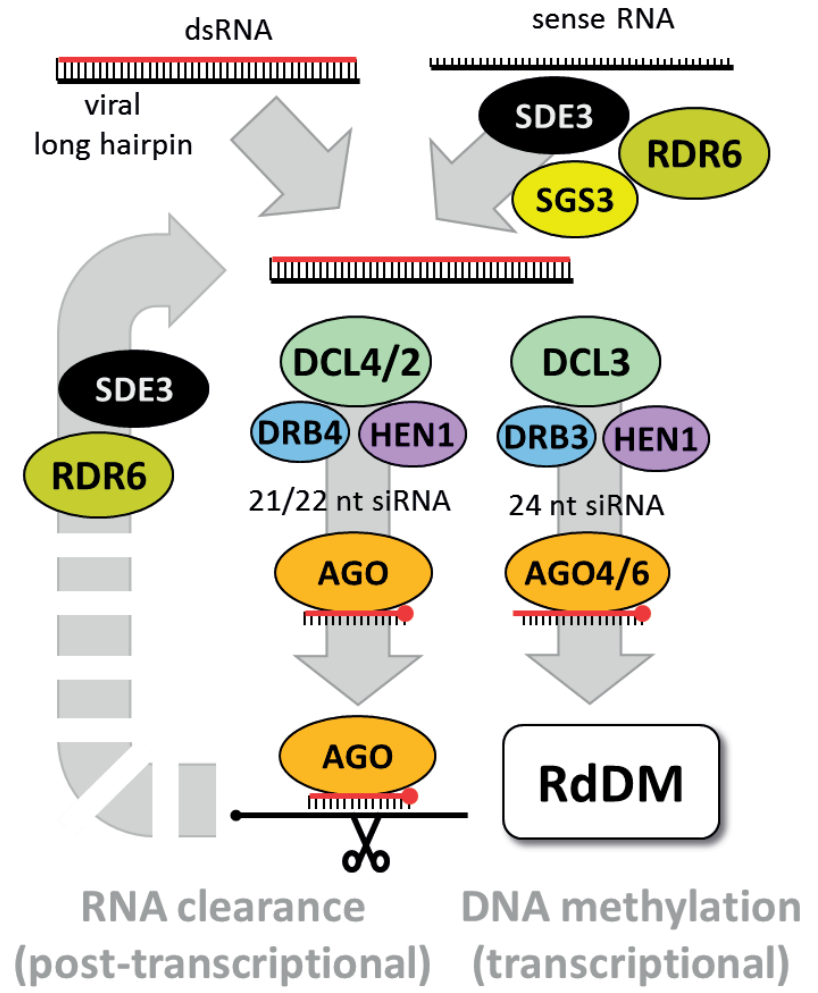

Figure 5 "RNAi module" of RNA silencing in Arabidopsis.

The key step in the RNAi module is conversion of different dsRNA into small RNAs by one of the DCL proteins, among which dominate DCL2/3/4. Some dsRNA is produced by RDR6 either as the initial trigger or as an amplification step where AGO-targeted RNAs are converted to dsRNA, which is processed into secondary siRNAs. If the targeting by AGO is precisely defined (e.g. by miRNA), the secondary siRNAs would be phased. DCL3-generated $24 \mathrm{nt}$ siRNAs can induce RdDM.

spread (Beclin et al., 1998; Ghoshroy et al., 1998). Later, it was also shown that phloem flow strongly influences the systemic spread of silencing in Nicotiana benthamiana and that the direction of systemic spread of silencing from inducer to sensor can be manipulated by altering sink/source relations in the plant (Tournier et al., 2006). Thus, systemic silencing is not an accidental stochastic process, but can be predicted according to the phloem flow direction (Tournier et al., 2006).

The systemic mobile signal could be various forms of RNA - small RNAs or their precursors. Identification of the systemic RNA silencing signal included analyses of the phloem sap and RNA behaviour upon various grafting experiments

Analysis of phloem sap found presence of siRNAs and miRNAs (Buhtz et al., 2008; Yoo et al., 2004). Subsequent grafting experiments suggested that all classes of small RNAs could be mobile while the systemic silencing signal was proposed to be the $24 \mathrm{nt}$ siRNA species (Himber et al., 2003; Melnyk et al., 2011a; Molnar et al., 2010). However, grafting 

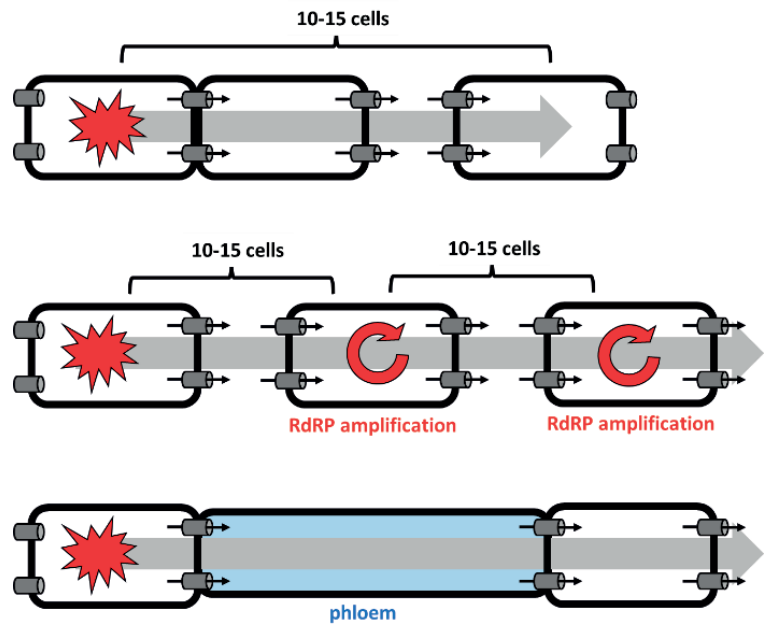

Figure 6 Movement of RNA silencing in plants.

In short-distance cell-to-cell movement, small RNAs move from the source cells where silencing was initiated (explosion pictogram) through plasmodesmata (symplastic route). Plasmodesmata are schematically depicted as tunnels in cell walls. Mobility is limited to $10-15$ cells. In long-range cell-cell movement, small RNA move again via plasmodesmata. Amplification (cycling arrow) of small RNAs by transitive small RNA production utilizing an RdRP activity extends the range of mobility far beyond the first 10-15 cells. In systemic movement, small RNAs enter the phloem and are transported to distant tissues

experiment with rootstocks lacking DCL2, 3, and 4 showed that such rootstocks still transmit the systemic silencing signal (Brosnan et al., 2007). This suggests that the silencing signal could be either long dsRNA precursor or siRNAs generated by DCL1, which normally generates miRNAs. Mobility of small RNAs was supported by NGS analysis of tissues lacking DCL2, 3, and 4, which could identify long dsRNA-derived 21, 22, and 24nt siRNAs (Molnar et al., 2010). Furthermore, the situation is complicated by secondary siRNAs, which emerge in the systemically silenced scion and degrade the target mRNA (Shimamura et al., 2007).

In any case, it is generally accepted that 24nt siRNA species are associated with systemic RNA silencing in plants but little is known concerning the exact form of systematically moving silencing RNAs. Since phloem transportation can accommodate relatively large molecules including mRNAs (reviewed in (Atkins et al., 2011; Hannapel et al., 2013)) mobility of small RNA precursors should not be excluded.

\section{Protein factors involved in systemic RNA silencing}

Consistent with involvement of 24nt siRNAs, four genes involved in a chromatin silencing pathway;NRPD1a, RDR2, and DCL3, are required for reception of long-distance mRNA silencing and an AGO4 mutant is also partially compromised in the reception of silencing (Brosnan et al., 2007). These data were corroborated by another study, which linked CLSY1, AGO4, RDR2, and NRPD1a to silencing spread (Smith et al., 2007). DCL3 appears to be the 
only DCL protein essential for systemic silencing (Melnyk et al., 2011a). In addition, RDR6 was implicated in systemic silencing where it seems to be involved in the perception of the silencing signal (Schwach et al., 2005) and its maintenance (Himber et al., 2003; Vaistij et al., 2002). RDR6 is amplifying decapped mRNAs cleaved by $24 \mathrm{nt}$ siRNAs. Subsequently. DCL4 and DCL2 act hierarchically to produce 21- and 22-nt siRNAs guiding mRNA cleavage mRNA degradation (Brosnan et al., 2007). Taken together, it appears that the systemic silencing employs both, post-transcriptional and transcriptional RNA silencing mechanisms. However, their integration in the systemic silencing process is still a matter of debate.

Interestingly, biochemical analysis of pumpkin (Cucurbita maxima) identified CmPSRP1 (PHLOEM SMALL RNA BINDING PROTEIN 1), which binds 25nt single-strand small RNAs in pumpkin and is a candidate protein for trafficking small single-strand RNA molecules (Yoo et al., 2004). Although there is additional supporting biochemical evidence for the role of CmPSRP1 in systemic silencing, there is no genetic support and its homologues across the plant kingdom are yet to be identified (Ham et al., 2014).

\section{Directionality of systemic RNA silencing}

Systemic silencing frequently flows in the common source-to-sink direction. This, however, does not preclude spreading in the opposite direction, which has also been observed. Below, I will discuss directionality of spreading between main plant parts.

\section{Shoot-to-root}

Depletion of shoot small RNAs corresponded to reduction of 24-nt small RNAs in wildtype roots, indicating that shoot-derived small RNAs contribute to the total root small RNA population as small RNAs in these grafted plants move predominantly from shoot to root following source-sink gradients (Molnar et al., 2010). This is was corroborated by a later study, which showed in Arabidopsis thaliana that 24-nt small RNAs are mobile from shoot to root (Melnyk et al., 2011b). This was further extended by showing that RNA-dependent DNA methylation in root tissues (occurring predominantly in non-CpG contexts) depends on mobile small RNAs from the shoot (Lewsey et al., 2016).

\section{Root-to-shoot:}

Upward (root-to-shoot) systemic silencing has also been reported from both, Nicotiana and Arabidopsis (Kasai et al., 2011; Kasai et al., 2013; Liang et al., 2012). For example, post-transcriptional silencing of an endogenous gene in the shoot was observed in Nicotiana when a wild-type scion was grafted on a rootstock synthesizing a siRNA signal (Kasai et al., 2011). The signal can spread from a rootstock can travel quite far as demonstrated in cherry, where siRNAs were detected $1.2 \mathrm{~m}$ from the graft union (Zhao and Song, 2014).

To what extent this type of spreading employs phloem is not clear. As mentioned above, while phloem flow the direction of systemic spread, it can be manipulated (Tournier et al., 2006). However, a study in Arabidopsis suggested that root-to-shoot signal movement might occur through plasmodesmata and not through the phloem (Liang et al., 2012). 


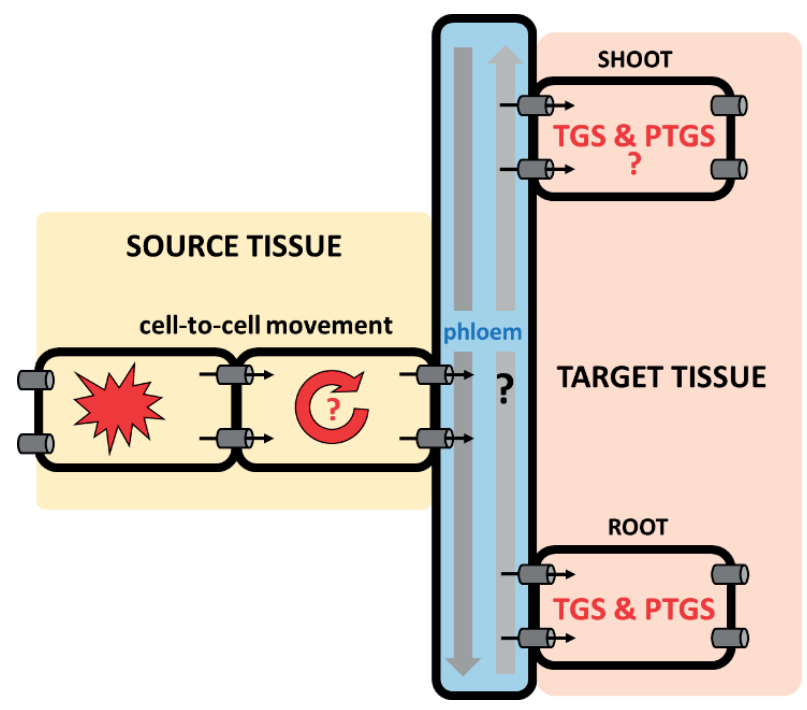

Figure 7 Systemic silencing mobility

Systemic silencing is initiated in the source tissue. The mobile silencing signal enters phloem and moves to the target tissue. Systemic silencing can occur in both directions, i.e. shoot-to-root and rootto-shoot. The shoot-to-root direction is following the common path of sugars to "sink" tissues. However, there is also evidence that systemic silencing can propagate in root-to-shoot direction.

Importantly, root-to-shoot spreading of RNA silencing is not a universal plant mechanism in vivo. It was shown that by RNA-mediated gene silencing signals are not graft transmissible from the rootstock to the scion in greenhouse-grown apple plants Malus sp. (Flachowsky et al., 2012). Further research is needed to reveal the molecular mechanisms and biological role(s) of the root-to-shoot (rootstock-scion) transmission of RNA silencing.

\section{Flower/seed concerning silencing spreading}

Some of the references addressed spreading of silencing in reproductive organs and seeds. It was shown that gamete formation requires AGO9, which controls female gamete formation in a non-cell autonomous manner (Olmedo-Monfil et al., 2010). In grafted Arabidopsis and Nicotiana the systemic silencing penetrated male sporogenic tissues suggesting that plants harbour an endogenous long-distance small RNA transport pathway facilitating siRNA signalling into meiotically active cells. (Zhang et al., 2014). Regarding seeds, an experiment targeting RNAi to the endosperm showed that RNAi was restricted to the endosperm tissue and that transitive RNAi did not occur (Hournard et al., 2007). Similarly, RNAi was observed to remain contained in the seed coat and did not spread to cotyledons and vegetative tissues (Tuteja et al., 2009). 
Table 1 Mutations that affect the cell-to-cell RNA silencing spreading phenotype in Arabidopsis adopted from (Melnyk et al., 2011b)

\begin{tabular}{|c|c|c|c|c|}
\hline \multicolumn{5}{|c|}{ Mutations that affect the cell-to-cell RNA silencing spreading phenotype in Arabidopsis } \\
\hline \multicolumn{5}{|c|}{ Mutations that reduce RNA silencing spread } \\
\hline mutation & type & gene & note & reference \\
\hline agol & inhib. & AGO1 & Argonaute, $21 \mathrm{nt}$ siRNA pathway & (Dunoyer et al., 2007) \\
\hline clsyl & inhib. & CLSY1 & SNF2-domain-containing protein & (Smith et al., 2007) \\
\hline$d c l 1$ & inhib. & DCL1 & $\begin{array}{l}\text { Dicer, miRNA \& } 21 \mathrm{nt} \text { siRNA } \\
\text { pathway }\end{array}$ & (Dunoyer et al., 2007) \\
\hline$d c l 4$ & inhib. & DCL4 & Dicer, $21 \mathrm{nt}$ siRNA pathway & (Dunoyer et al., 2005; Smith et al., 2007) \\
\hline fca & inhib. & FCA & & (Baurle et al., 2007) \\
\hline$f p a$ & inhib. & FPA & & (Baurle et al., 2007) \\
\hline$f y$ & inhib. & FY & & (Manzano et al., 2009) \\
\hline jmj14 & inhib. & JMJ14 & $\begin{array}{l}\text { histone } \mathrm{H} 3 \mathrm{~K} 4 \text { demethylase } \\
\text { linked to non-CpG methylation }\end{array}$ & (Searle et al., 2010) \\
\hline hen1 & inhib. & HEN1 & small RNA methylase & (Dunoyer et al., 2007) \\
\hline hprl & inhib. & HPR1 & RNA trafficking protein & (Jauvion et al., 2010) \\
\hline $\begin{array}{l}\text { nrpdl/ } \\
\text { smdl }\end{array}$ & inhib. & NPRD1 & plant RNA pol-IV component & $\begin{array}{l}\text { (Brosnan et al., 2007; Dunoyer et al., } \\
\text { 2007; Dunoyer et al., 2005; Smith et al., } \\
\text { 2007) }\end{array}$ \\
\hline$n r p d 2 a$ & inhib. & NRPDA2 & & (Smith et al., 2007) \\
\hline$r d r 2 / s m d 2$ & inhib. & RDR2 & plant RNA pol-IV component & $\begin{array}{l}\text { (Brosnan et al., 2007; Dunoyer et al., } \\
\text { 2007; Dunoyer et al., 2005; Smith et al., } \\
\text { 2007) }\end{array}$ \\
\hline $\operatorname{smd3}$ & inhib. & SMD3 & silencing movement deficient & (Dunoyer et al., 2005) \\
\hline $\operatorname{texl}$ & stim & TEX1 & mRNA export complex & (Yelina et al., 2010) \\
\hline \multirow[t]{2}{*}{$\operatorname{ago4}$} & stim & \multirow[t]{2}{*}{ AGO4 } & Argonaute, & (Searle et al., 2010; Smith et al., 2007) \\
\hline & inhib & & $\begin{array}{l}\text { partially compromised reception } \\
\text { of silencin }\end{array}$ & (Brosnan et al., 2007) \\
\hline \multirow[t]{2}{*}{$d c l 3^{b}$} & stim & \multirow[t]{2}{*}{ DCL3 } & & (Smith et al., 2007) \\
\hline & inhib & & & (Brosnan et al., 2007) \\
\hline
\end{tabular}

\section{Summary}

Taken together, it seems that there is no an exclusive mobile small RNA species. Rather, there may be more forms of small mobile RNAs. At the moment, there is no definite consensus on specific mechanism(s) regulating sorting of small RNAs into mobile and cell-autonomous small RNAs.

\section{Addendum}

I feel obliged to mention an incident which stirred the RNA silencing field and affected the literature on systemic RNA silencing in plants. In January 2015, a number of publications 
authored by Olivier Voinnet was brought up as potentially containing manipulated images at a server PubPeer.com. Among these were highly cited publications that laid foundations of RNA silencing research in plants. A subsequent ethical committee investigation concluded that publications indeed contained manipulated figures. the following Voinnet's publications had to be corrected or retracted:

\section{Retractions:}

1. Brigneti G.et al.,EMBO J (1998)

2. Voinnet, O.et al., Plant J. 33: 949-56 (2003)

3. Dunoyer P.et al., Plant Cell 16: 1235-50 (2004)

4. Moissiard G. and Voinnet O., Proc. Nat. Acad. Sci.USA 103 (51): 19593 (2006)

5. Dunoyer P.et al., EMBO J (2010)

6. Dunoyer P. et al., Science 328 (5980), 912 (2010)

7. Ciaudo C.et al., PLoS Genetics 9(11): e1003791 (2013)

8. Sansregret R.et al., PLoS Pathogens 1(9): e1005207 (2013)

\section{Corrections:}

1. Ruiz MT et al, Plant Cell10: 937-946 (1998)

2. Voinnet O, et al., Nat.l Acad. Sci.USA 96:14147-14152; (1999)

4. Dunoyer P.et al., Plant J. 29: 555-67 (2002)

3. Hamilton A.et al., EMBO J (2002)

5. Parizotto E.A.et al., Genes \& Development 18: 2237-42 (2004) - 2nd

Correction:

8. Deleris A. et al, Science 313(5783): 68-71 (2006)

6. Dunoyer P.et al., Nature Genetics 38: 258-63 (2006)

7. Navarro L. et al., Science 312(5772): 436-439 (2006)

9. Moissiard et al, RNA 13: 1268-1278 (2007)

10. Haas G. et al, EMBO J 27, 2102-2112 (2008)

11. Ciaudo C.et al., PLoS Genetics 5(8): e1000620 (2009)

12. Bennasser Y et al., Nat. Struct. Mol. Biol. 18, 323-327 (2011)

13. Jay F, et al. (2011) PLoS Pathog 7(5): e1002035

14. Brodersen P.et al., Proc. Nat.l Acad. Sci. USA 109: 1778-83 (2012)

15. Gibbings D. et al, Nature Cell Biology 14, 1314-1321 (2012)

16. Schott G. et al, EMBO J 31, 2553-2565 (2012)

17. Boccara M.,et al., PLoS Pathogens 10(1): e1003883 (2014)

Further details about the affair can be found, for example, here: http://retractionwatch.com/category/by-author/olivier-voinnet/ http://labtimes.org/editorial/e_594.lasso http://labtimes.org/editorial/e_600.lasso http://labtimes.org/editorial/e_623.lasso http://labtimes.org/editorial/e_624.lasso 


\section{Acknowledgement}

I would like to thank my colleagues Jan Paces, Miloslav Nic, and Tomas Novotny for help with collecting literature for the review. The review content was produced under a contract OC/EFSA/GMO/2015/01-CT 01 with European Food Safety Authority (EFSA); the opinions expressed are those of the contractor only and do not represent EFSA's official position. Publication of the review was funded by LO1220 and LM2015063 by the Ministry of Education, Youth and Sports.

\section{References}

Atkins, C.A., Smith, P.M., and Rodriguez-Medina, C. (2011). Macromolecules in phloem exudates--a review. Protoplasma 248, 165-172.

Baurle, I., Smith, L., Baulcombe, D.C., and Dean, C. (2007). Widespread role for the flowering-time regulators FCA and FPA in RNA-mediated chromatin silencing. Science 318, 109-112.

Beclin, C., Berthome, R., Palauqui, J.C., Tepfer, M., and Vaucheret, H. (1998). Infection of tobacco or Arabidopsis plants by CMV counteracts systemic post-transcriptional silencing of nonviral (trans) genes. Virology 252, 313-317.

Borges, F., and Martienssen, R.A. (2015). The expanding world of small RNAs in plants. Nature Reviews Molecular Cell Biology 16, 727-741.

Brosnan, C.A., Mitter, N., Christie, M., Smith, N.A., Waterhouse, P.M., and Carroll, B.J. (2007). Nuclear gene silencing directs reception of long-distance mRNA silencing in Arabidopsis. America 104, 14741-14746.

Brosnan, C.A., and Voinnet, O. (2011). Cell-to-cell and long-distance siRNA movement in plants: mechanisms and biological implications. Curr Opin Plant Biol 14, 580-587.

Buhtz, A., Pieritz, J., Springer, F., and Kehr, J. (2010). Phloem small RNAs, nutrient stress responses, and systemic mobility. BMC Plant Biol 10, 64 .

Buhtz, A., Springer, F., Chappell, L., Baulcombe, D.C., and Kehr, J. (2008). Identification and characterization of small RNAs from the phloem of Brassica napus. Plant J 53, 739-749.

Chitwood, D.H., Nogueira, F.T., Howell, M.D., Montgomery, T.A., Carrington, J.C., and Timmermans, M.C. (2009). Pattern formation via small RNA mobility. Genes Dev 23, 549-554.

de Felippes, F.F., Ott, F., and Weigel, D. (2011). Comparative analysis of non-autonomous effects of tasiRNAs and miRNAs in Arabidopsis thaliana. Nucleic Acids Research 39, 2880-2889.

De Schepper, V., De Swaef, T., Bauweraerts, I., and Steppe, K. (2013). Phloem transport: a review of mechanisms and controls. J Exp Bot 64, 4839-4850.

Dunoyer, P., Himber, C., Ruiz-Ferrer, V., Alioua, A., and Voinnet, O. (2007). Intra- and intercellular RNA interference in Arabidopsis thaliana requires components of the microRNA and heterochromatic silencing pathways. Nature Genetics 39, 848-856.

Dunoyer, P., Himber, C., and Voinnet, O. (2005). DICER-LIKE 4 is required for RNA interference and produces the 21-nucleotide small interfering RNA component of the plant cell-to-cell silencing signal. Nature Genetics 37, 1356-1360. 
Fei, Q., Yang, L., Liang, W., Zhang, D., and Meyers, B.C. (2016). Dynamic changes of small RNAs in rice spikelet development reveal specialized reproductive phasiRNA pathways. J Exp Bot 67, 6037-6049.

Flachowsky, H., Trankner, C., Szankowski, I., Waidmann, S., Hanke, M.V., Treutter, D., and Fischer, T.C. (2012). RNA-mediated gene silencing signals are not graft transmissible from the rootstock to the scion in greenhouse-grown apple plants Malus sp. Int J Mol Sci 13, 9992-10009.

Ghoshroy, S., Freedman, K., Lartey, R., and Citovsky, V. (1998). Inhibition of plant viral systemic infection by non-toxic concentrations of cadmium. Plant J 13, 591-602.

Grant-Downton, R., Le Trionnaire, G., Schmid, R., Rodriguez-Enriquez, J., Hafidh, S., Mehdi, S., Twell, D., and Dickinson, H. (2009). MicroRNA and tasiRNA diversity in mature pollen of Arabidopsis thaliana. Bmc Genomics 10, 643-643.

Guan, D., Yan, B., Thieme, C., Hua, J., Zhu, H., Boheler, K.R., Zhao, Z., Kragler, F., Xia, Y., and Zhang, S. (2017). PlaMoM: a comprehensive database compiles plant mobile macromolecules. Nucleic Acids Res 45, D1021-D1028.

Ham, B.K., Li, G., Jia, W., Leary, J.A., and Lucas, W.J. (2014). Systemic delivery of siRNA in pumpkin by a plant PHLOEM SMALL RNA-BINDING PROTEIN 1-ribonucleoprotein complex. Plant J 80, 683-694.

Hamilton, A., Voinnet, O., Chappell, L., and Baulcombe, D. (2002). Two classes of short interfering RNA in RNA silencing. Embo Journal 21, 4671-4679.

Hannapel, D.J., Sharma, P., and Lin, T. (2013). Phloem-mobile messenger RNAs and root development. Front Plant Sci 4, 257.

Heisel, S.E., Zhang, Y.J., Allen, E., Guo, L., Reynolds, T.L., Yang, X., Kovalic, D., and Roberts, J.K. (2008). Characterization of Unique Small RNA Populations from Rice Grain. Plos One 3, e2871-e2871.

Himber, C., Dunoyer, P., Moissiard, G., Ritzenthaler, C., and Voinnet, O. (2003). Transitivity-dependent and -independent cell-to-cell movement of RNA silencing. The EMBO journal 22, 4523-4533.

Hournard, N.M., Mainville, J.L., Bonin, C.P., Huang, S., Luethy, M.H., and Malvar, T.M. (2007). High-lysine corn generated by endosperm-specific suppression of lysine catabolism using RNAi. Plant Biotechnology Journal 5, 605-614.

Jauvion, V., Elmayan, T., and Vaucheret, H. (2010). The conserved RNA trafficking proteins HPR1 and TEX1 are involved in the production of endogenous and exogenous small interfering RNA in Arabidopsis. Plant Cell 22, 2697-2709.

Jeong, D.H., Park, S., Zhai, J., Gurazada, S.G., De Paoli, E., Meyers, B.C., and Green, P.J. (2011). Massive analysis of rice small RNAs: mechanistic implications of regulated microRNAs and variants for differential target RNA cleavage. Plant Cell 23, 4185-4207.

Jorgensen, R.A. (1995). Cosuppression, flower color patterns, and metastable gene expression States. Science 268, 686-691.

Kalantidis, K., Tsagris, M., and Tabler, M. (2006). Spontaneous short-range silencing of a GFP transgene in Nicotiana benthamiana is possibly mediated by small quantities of siRNA that do not trigger systemic silencing. Plant Journal 45, 1006-1016.

Kapoor, M., Arora, R., Lama, T., Nijhawan, A., Khurana, J.P., Tyagi, A.K., and Kapoor, S. (2008). Genome-wide identification, organization and phylogenetic analysis of Dicer-like, Argonaute and RNA-dependent RNA Polymerase gene families and their expression analysis during reproductive development and stress in rice. BMC Genomics 9, 451. 
Kasai, A., Bai, S.L., Li, T.Z., and Harada, T. (2011). Graft-Transmitted siRNA Signal from the Root Induces Visual Manifestation of Endogenous Post-Transcriptional Gene Silencing in the Scion. Plos One 6, e16895-e16895.

Kasai, A., Sano, T., and Harada, T. (2013). Scion on a Stock Producing siRNAs of Potato Spindle Tuber Viroid (PSTVd) Attenuates Accumulation of the Viroid. Plos One 8, e57736-e57736.

Knauer, S., Holt, A.L., Rubio-Somoza, I., Tucker, E.J., Hinze, A., Pisch, M., Javelle, M., Timmermans, M.C., Tucker, M.R., and Laux, T. (2013). A Protodermal miR394 Signal Defines a Region of Stem Cell Competence in the Arabidopsis Shoot Meristem. Developmental Cell 24, 125-132.

Kobayashi, K., and Zambryski, P. (2007). RNA silencing and its cell-to-cell spread during Arabidopsis embryogenesis. Plant Journal 50, 597-604.

Lewsey, M.G., Hardcastle, T.J., Melnyk, C.W., Molnar, A., Valli, A., Urich, M.A., Nery, J.R., Baulcombe, D.C., and Ecker, J.R. (2016). Mobile small RNAs regulate genome-wide DNA methylation. America 113, E801-E810.

Li, J., Yang, Z., Yu, B., Liu, J., and Chen, X. (2005). Methylation protects miRNAs and siRNAs from a 3'-end uridylation activity in Arabidopsis. Curr Biol 15, 1501-1507.

Liang, D.C., White, R.G., and Waterhouse, P.M. (2012). Gene Silencing in Arabidopsis Spreads from the Root to the Shoot, through a Gating Barrier, by Template-Dependent, Nonvascular, Cell-to-Cell Movement. Plant Physiology 159, 984-1000.

Lin, S.I., Chiang, S.F., Lin, W.Y., Chen, J.W., Tseng, C.Y., Wu, P.C., and Chiou, T.J. (2008). Regulatory network of microRNA399 and PHO2 by systemic signaling. Plant Physiology 147, 732-746.

Manzano, D., Marquardt, S., Jones, A.M., Baurle, I., Liu, F., and Dean, C. (2009). Altered interactions within FY/AtCPSF complexes required for Arabidopsis FCA-mediated chromatin silencing. Proc Natl Acad Sci U S A 106, 8772-8777.

Marin, E., Jouannet, V., Herz, A., Lokerse, A.S., Weijers, D., Vaucheret, H., Nussaume, L., Crespi, M.D., and Maizel, A. (2010). miR390, Arabidopsis TAS3 tasiRNAs, and their AUXIN RESPONSE FACTOR targets define an autoregulatory network quantitatively regulating lateral root growth. Plant Cell 22, 1104-1117.

Maule, A.J. (2008). Plasmodesmata: structure, function and biogenesis. Curr Opin Plant Biol 11, 680-686.

Maule, A.J., Benitez-Alfonso, Y., and Faulkner, C. (2011). Plasmodesmata - membrane tunnels with attitude. Curr Opin Plant Biol 14, 683-690.

McHale, M., Eamens, A.L., Finnegan, E.J., and Waterhouse, P.M. (2013). A 22-nt artificial microRNA mediates widespread RNA silencing in Arabidopsis. Plant Journal 76, 519-529.

Melnyk, C.W., Molnar, A., Bassett, A., and Baulcombe, D.C. (2011a). Mobile 24 nt Small RNAs Direct Transcriptional Gene Silencing in the Root Meristems of Arabidopsis thaliana. Current Biology 21, 1678-1683.

Melnyk, C.W., Molnar, A., and Baulcombe, D.C. (2011b). Intercellular and systemic movement of RNA silencing signals. The EMBO journal 30, 3553-3563.

Mittal, D., Mukherjee, S.K., Vasudevan, M., and Mishra, N.S. (2013). Identification of Tissue-Preferential Expression Patterns of Rice miRNAs. Journal of Cellular Biochemistry 114, 2071-2081. Miyashima, S., Koi, S., Hashimoto, T., and Nakajima, K. (2011). Non-cell-autonomous microRNA165 acts in a dose-dependent manner to regulate multiple differentiation status in the Arabidopsis root. Development 138, 2303-2313. 
Molnar, A., Melnyk, C.W., Bassett, A., Hardcastle, T.J., Dunn, R., and Baulcombe, D.C. (2010). Small Silencing RNAs in Plants Are Mobile and Direct Epigenetic Modification in Recipient Cells. Science 328, 872-875.

Nakano, M., Nobuta, K., Vemaraju, K., Tej, S.S., Skogen, J.W., and Meyers, B.C. (2006). Plant MPSS databases: signature-based transcriptional resources for analyses of mRNA and small RNA. Nucleic Acids Res 34, D731-735.

Napoli, C., Lemieux, C., and Jorgensen, R. (1990). Introduction of a Chimeric Chalcone Synthase Gene into Petunia Results in Reversible Co-Suppression of Homologous Genes in trans. Plant Cell 2, 279-289.

Nobuta, K., Venu, R.C., Lu, C., Belo, A., Vemaraju, K., Kulkarni, K., Wang, W.Z., Pillay, M., Green, P.J., Wang, G.L., et al. (2007). An expression atlas of rice mRNAs and small RNAs. Nature Biotechnology 25, 473-477.

Olmedo-Monfil, V., Duran-Figueroa, N., Arteaga-Vazquez, M., Demesa-Arevalo, E., Autran, D., Grimanelli, D., Slotkin, R.K., Martienssen, R.A., and Vielle-Calzada, J.P. (2010). Control of female gamete formation by a small RNA pathway in Arabidopsis. Nature 464, 628-U200.

Palauqui, J.C., Elmayan, T., Pollien, J.M., and Vaucheret, H. (1997). Systemic acquired silencing: transgene-specific post-transcriptional silencing is transmitted by grafting from silenced stocks to non-silenced scions. The EMBO journal 16, 4738-4745.

Pant, B.D., Buhtz, A., Kehr, J., and Scheible, W.R. (2008). MicroRNA399 is a long-distance signal for the regulation of plant phosphate homeostasis. Plant Journal 53, 731-738.

Ratcliff, F., Harrison, B.D., and Baulcombe, D.C. (1997). A similarity between viral defense and gene silencing in plants. Science 276, 1558-1560.

Ryabov, E.V., van Wezel, R., Walsh, J., and Hong, Y. (2004). Cell-to-cell, but not long-distance, spread of RNA silencing that is induced in individual epidermal cells. Journal of Virology 78 , 3149-3154.

Schwab, R., Maizel, A., Ruiz-Ferrer, V., Garcia, D., Bayer, M., Crespi, M., Voinnet, O., and Martienssen, R.A. (2009). Endogenous TasiRNAs Mediate Non-Cell Autonomous Effects on Gene Regulation in Arabidopsis thaliana. Plos One 4, e5980-e5980.

Schwach, F., Vaistij, F.E., Jones, L., and Baulcombe, D.C. (2005). An RNA-dependent RNA polymerase prevents meristem invasion by potato virus $\mathrm{X}$ and is required for the activity but not the production of a systemic silencing signal. Plant Physiology 138, 1842-1852.

Searle, I.R., Pontes, O., Melnyk, C.W., Smith, L.M., and Baulcombe, D.C. (2010). JMJ14, a JmjC domain protein, is required for RNA silencing and cell-to-cell movement of an RNA silencing signal in Arabidopsis. Genes \& Development 24, 986-991.

Shimamura, K., Oka, S., Shimotori, Y., Ohmori, T., and Kodama, H. (2007). Generation of secondary small interfering RNA in cell-autonomous and non-cell autonomous RNA silencing in tobacco. Plant Molecular Biology 63, 803-813.

Smith, L.M., Pontes, O., Searle, L., Yelina, N., Yousafzai, F.K., Herr, A.J., Pikaard, C.S., and Baulcombe, D.C. (2007). An SNF2 protein associated with nuclear RNA silencing and the spread of a silencing signal between cells in Arabidopsis. Plant Cell 19, 1507-1521.

Svoboda, P. (2019). RNAi and miRNA pathways in plants I - molecular mechanisms.

Tournier, B., Tabler, M., and Kalantidis, K. (2006). Phloem flow strongly influences the systemic spread of silencing in GFP Nicotiana benthamiana plants. Plant Journal 47, 383-394. 
Turgeon, R., and Wolf, S. (2009). Phloem transport: cellular pathways and molecular trafficking. Annu Rev Plant Biol 60, 207-221.

Tuteja, J.H., Zabala, G., Varala, K., Hudson, M., and Vodkin, L.O. (2009). Endogenous, Tissue-Specific Short Interfering RNAs Silence the Chalcone Synthase Gene Family in Glycine max Seed Coats. Plant Cell 21, 3063-3077.

Vaistij, F.E., Jones, L., and Baulcombe, D.C. (2002). Spreading of RNA targeting and DNA methylation in RNA silencing requires transcription of the target gene and a putative RNA-dependent RNA polymerase. Plant Cell 14, 857-867.

Valoczi, A., Varallyay, E., Kauppinen, S., Burgyan, J., and Havelda, Z. (2006). Spatio-temporal accumulation of microRNAs is highly coordinated in developing plant tissues. Plant Journal 47, $140-151$.

Voinnet, O., and Baulcombe, D.C. (1997). Systemic signalling in gene silencing. Nature 389, 553.

Voinnet, O., Vain, P., Angell, S., and Baulcombe, D.C. (1998). Systemic spread of sequence-specific transgene RNA degradation in plants is initiated by localized introduction of ectopic promoterless DNA. Cell 95, 177-187.

Voinnet, O., Vain, P., Angell, S., and Baulcombe, D.C. (2016). Systemic Spread of Sequence-Specific Transgene RNA Degradation in Plants Is Initiated by Localized Introduction of Ectopic Promoterless DNA. Cell 166, 779.

Yelina, N.E., Smith, L.M., Jones, A.M., Patel, K., Kelly, K.A., and Baulcombe, D.C. (2010). Putative Arabidopsis THO/TREX mRNA export complex is involved in transgene and endogenous siRNA biosynthesis. Proc Natl Acad Sci U S A 107, 13948-13953.

Yoo, B.C., Kragler, F., Varkonyi-Gasic, E., Haywood, V., Archer-Evans, S., Lee, Y.M., Lough, T.J., and Lucas, W.J. (2004). A systemic small RNA signaling system in plants. Plant Cell 16, 1979-2000.

Zabala, G., Campos, E., Varala, K.K., Bloomfield, S., Jones, S.I., Win, H., Tuteja, J.H., Calla, B., Clough, S.J., Hudson, M., et al. (2012). Divergent patterns of endogenous small RNA populations from seed and vegetative tissues of Glycine max. Bmc Plant Biology 12, 177-177.

Zhang, W.N., Kollwig, G., Stecyk, E., Apelt, F., Dirks, R., and Kragler, F. (2014). Graft-transmissible movement of inverted-repeat-induced siRNA signals into flowers. Plant Journal 80, 106-121.

Zhao, D., and Song, G.Q. (2014). Rootstock-to-scion transfer of transgene-derived small interfering RNAs and their effect on virus resistance in nontransgenic sweet cherry. Plant Biotechnol J 12, 1319-1328.

Zhu, Q.H., Spriggs, A., Matthew, L., Fan, L.J., Kennedy, G., Gubler, F., and Helliwell, C. (2008). A diverse set of microRNAs and microRNA-like small RNAs in developing rice grains. Genome Research 18, 1456-1465. 